University of Nebraska - Lincoln

DigitalCommons@University of Nebraska - Lincoln

3-1-1995

\title{
Excess Heat Capacity Surfaces for Water-Alkanol Mixtures by the UNIQUAC Model
}

Yasar Demirel

University of Nebraska-Lincoln, ydemirel2@unl.edu

Follow this and additional works at: https://digitalcommons.unl.edu/chemengphysical

Part of the Chemical Engineering Commons

Demirel, Yasar, "Excess Heat Capacity Surfaces for Water-Alkanol Mixtures by the UNIQUAC Model" (1995). Papers in Physical Chemistry. 5.

https://digitalcommons.unl.edu/chemengphysical/5

This Article is brought to you for free and open access by the Chemical and Biomolecular Engineering Research and Publications at DigitalCommons@University of Nebraska - Lincoln. It has been accepted for inclusion in Papers in Physical Chemistry by an authorized administrator of DigitalCommons@University of Nebraska - Lincoln. 


\title{
Excess Heat Capacity Surfaces for Water-Alkanol Mixtures by the UNIQUAC Model
}

\begin{abstract}
Hydroorganic mixtures are industrial solvents that can serve as media to solubilize either water in hydrocarbon or a hydrophobic substance in water. In many cases the solubilizing capability is obtained via a homogeneous complex aqueous mixtures containing an alcohol. Since excess heat capacity, $C_{\mathrm{p}}^{\mathrm{E}}$, is very sensitive to structural changes in mixtures, concentration and temperature dependence of $C_{\mathrm{p}}^{\mathrm{E}}$ have been calculated by using the UNIQUAC model for the mixtures methanol(1)-water(2), ethanol(1)-water(2), and 1-propanol(1)-water(2). The temperature-dependent parameters of the model estimated directly from $C_{\mathrm{p}}^{E}$ data at more than one different isotherm are used in the calculations. The overall deviations between the calculated and experimental data points change in the range $6.52-10.15 \%$, which indicates the satisfactory representation of $C_{\mathrm{p}}^{\mathrm{E}}$ data by the model for engineering calculations. The temperature range of experimental data for the mixtures is 288.15 and $308.15 \mathrm{~K}$. Surfaces of reduced, apparent, and partial molar excess heat capacities are also derived. The concentration and temperature dependencies of these functions suggest the existence of transitions of microstructure in the water-rich region, qualitatively similar to micellization. The surface of these thermodynamic functions facilitates a better understanding of thermodynamic properties and association of alcohol-water mixtures over a whole or certain concentration and temperature range. Such thermodynamic surfaces may be represented satisfactorily by the UNIQUAC model at low pressures.
\end{abstract}

Comment: This paper was published in the journal of "Industrial and Engineering Chemistry Research" 1995. And all the copy rights C of this paper belong to American Chemical Society. 
Table 1. Deviations between the Experimental and Calculated Excess Heat Capacity, $C_{p}^{E}$, Data by the UNIQUAC Model

\begin{tabular}{lccc}
\hline \multicolumn{1}{c}{$\begin{array}{c}\text { system } \\
\text { reference }\end{array}$} & $n$ & $T\left({ }^{\circ} \mathrm{C}\right)$ & $D\left(C_{p}^{E^{E}}\right)$ \\
\hline 1. methanol(1)-water(2) & 21 & 15 & 18.39 \\
Benson and D'Arcy, 1982 & 19 & 25 & 6.94 \\
Ogawa and Murakami, 1986 & 22 & 35 & 5.13 \\
& & & $10.15^{a}$ \\
2. ethanol(1)-water(2) & 15 & 15 & 7.92 \\
Benson and D'Arcy, 1982 & 17 & 25 & 5.98 \\
Ogawa and Murakami, 1986 & 22 & 35 & 8.71 \\
& & & $7.53^{a}$ \\
3. 1-propanol(1)-water(2) & 22 & 15 & 9.01 \\
Benson and D'Arcy, 1982 & 22 & 25 & 4.77 \\
Ogawa and Murakami, 1986 & 21 & 30 & 5.78 \\
& & & $6.52^{a}$
\end{tabular}

${ }^{a}$ Overall deviation.

deviations are obtained from the following equation:

$$
D\left(C_{\mathrm{p}}^{\mathrm{E}}\right)=(1 / n) \sum_{i}^{n}\left[\left|\left(C_{\mathrm{p}, \text { exptl }}^{\mathrm{E}}-C_{\mathrm{p}, \text { calcd }}^{\mathrm{E}}\right)\right| / C_{\mathrm{p}, \text { expt }}^{\mathrm{E}}\right]_{i} \times 100
$$
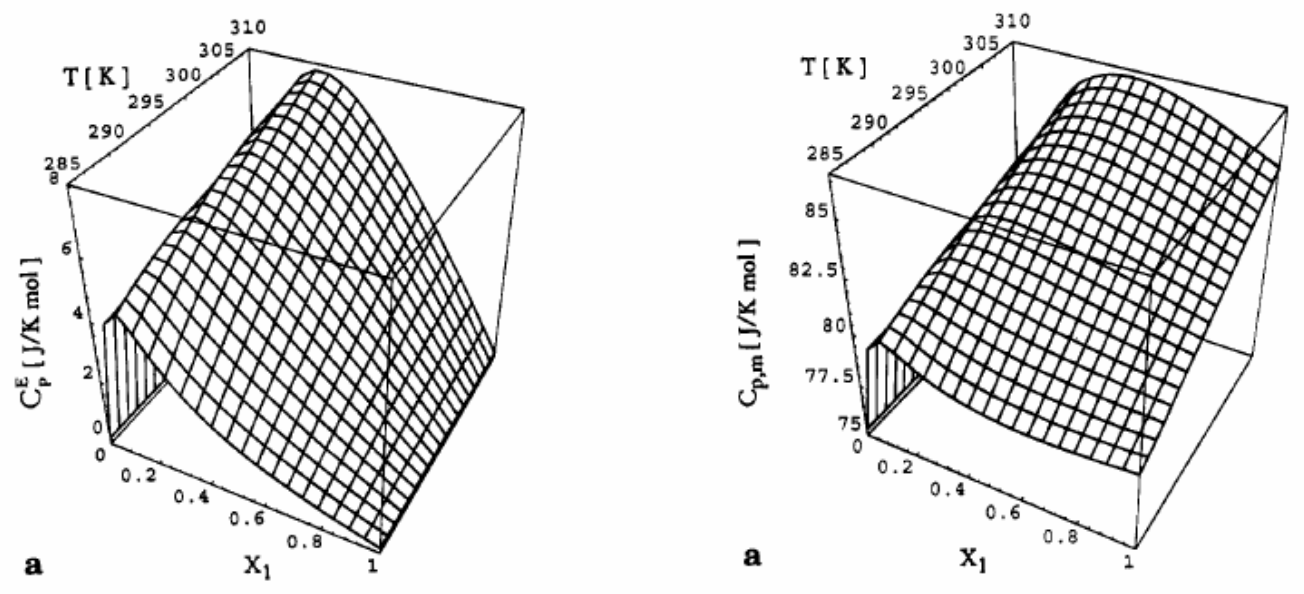

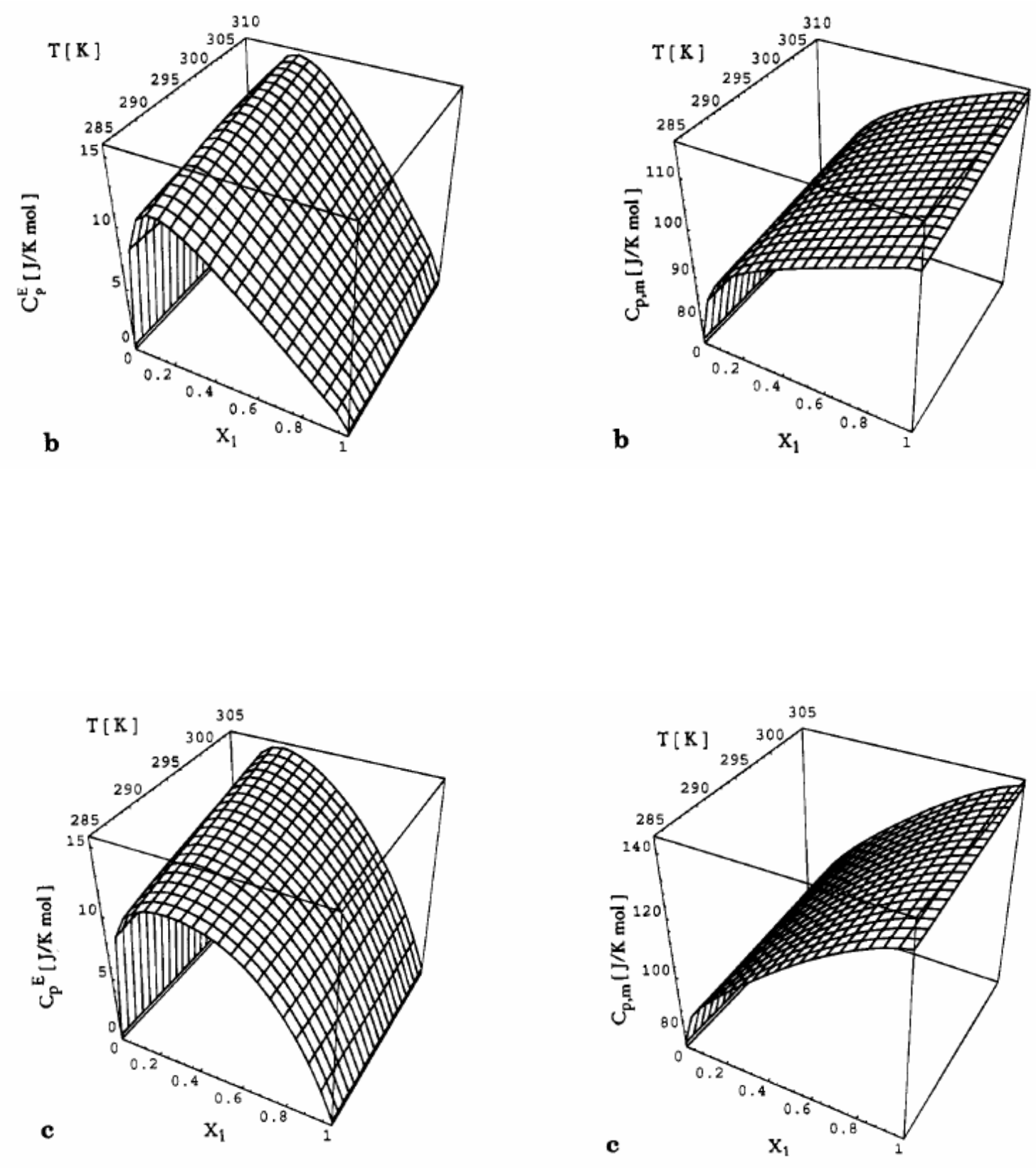

Figure 1. Concentration and temperature dependence of excess heat capacity surfaces. (a) methanol(1)-water(2) for 285.15$310.15 \mathrm{~K}$; (b) ethanol(1)-water(2) for 285.15-310.K; (c) 1-propanol(1)-water(2) for $285.15-305.15 \mathrm{~K}$.

Figure 2. Concentration and temperature dependence of molar heat capacity of mixtures. (a) methanol(1)-water(2) for 285.15$310.15 \mathrm{~K}$; (b) ethanol(1)-water(2) for $285.15-310 . \mathrm{K}$; (c) 1-propanol(1)-water(2) for $285.15-305.15 \mathrm{~K}$. 

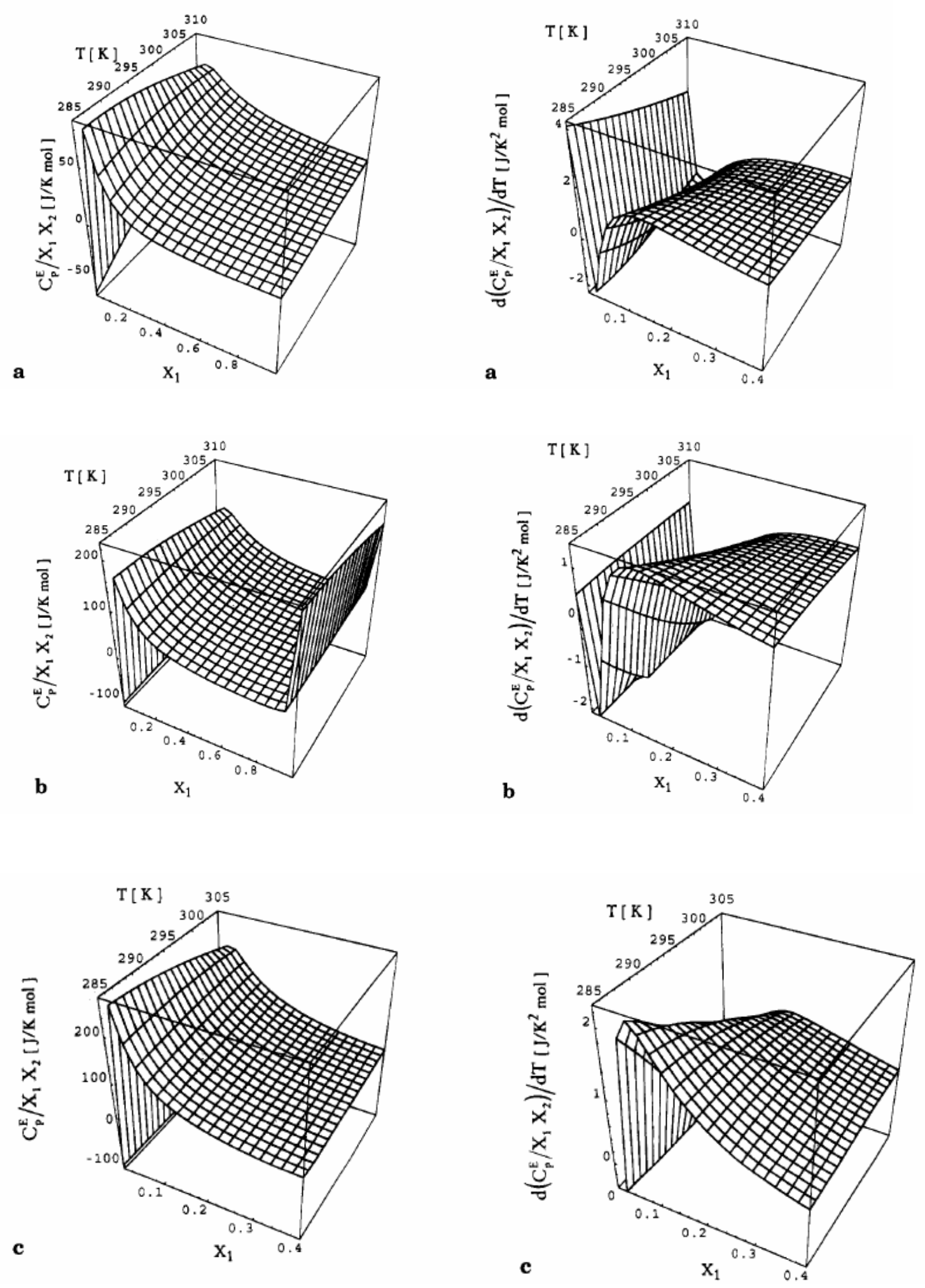

Figure 3. Concentration and temperature dependence of reduced heat capacity. (a) methanol(1)-water(2) for $285.15-310.15 \mathrm{~K}$; (b) ethanol(1)-water(2) for 285.15-310.K; (c) 1-propanol(1)-water(2) for $285.15-305.15 \mathrm{~K}$.

Figure 4. Concentration and temperature dependence of temperature derivative of reduced heat capacity in the water-rich region: (a) methanol(1)-water(2) for $285.15-310.15 \mathrm{~K}$; (b) ethanol(1)-water(2) for $285.15-310 . K$; (c) 1-propanol(1)-water(2) for $285.15-305.15 \mathrm{~K}$. 

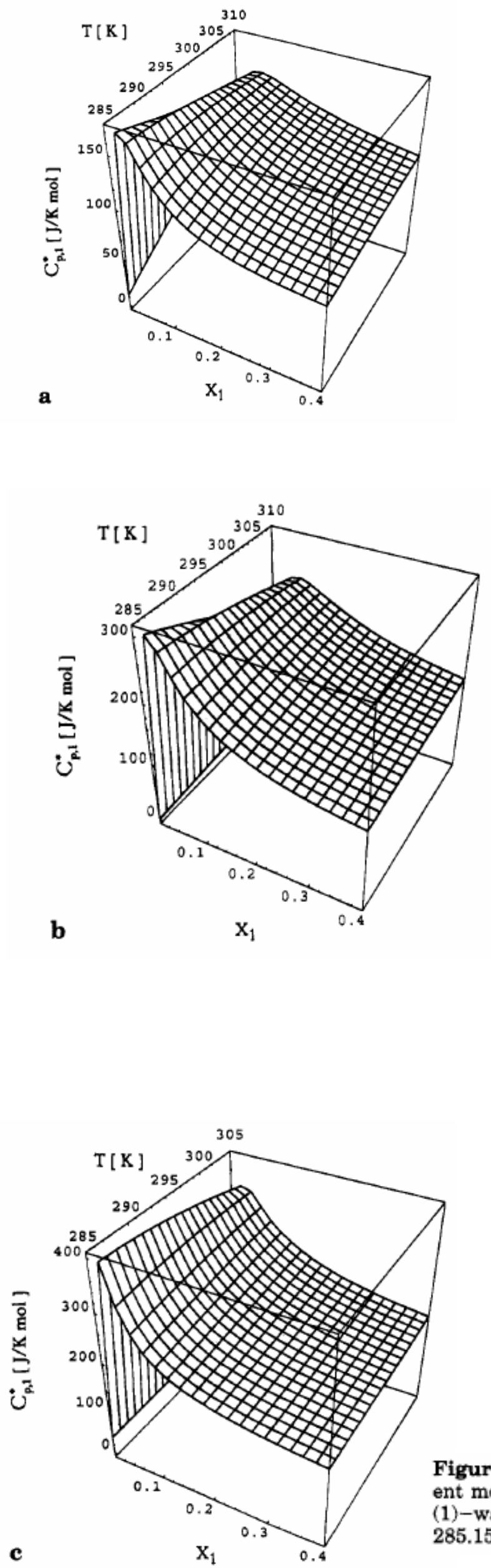

Figure 5. Concentration and temperature dependence of apparent molar heat capacity in the water-rich region: (a) methanol(1) - water(2) for 285.15-310.15 K; (b) ethanol(1)-water(2) for $285.15-310 . \mathrm{K}$; (c) 1-propanol(1)-water(2) for $285.15-305.15 \mathrm{~K}$. 

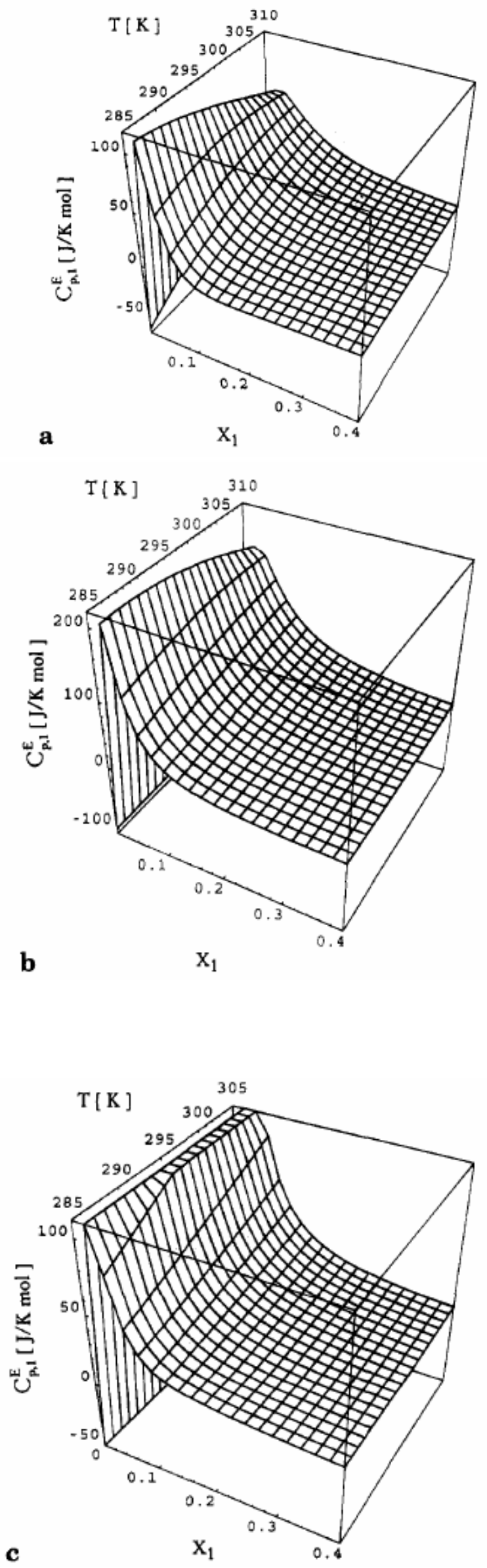

Figure 6. Concentration and temperature dependence of partial molar excess heat capacity in the water-rich region. (a) methanol(1) -water(2) for $285.15-310.15 \mathrm{~K}$; (b) ethanol(1)-water(2) for 285.15-310.K; (c) 1-propanol(1)-water(2) for 285.15-305.15 K. 